\title{
Updates on the cytogenetics and molecular cytogenetics of benign and intermediate soft tissue tumors (Review)
}

\author{
JUN NISHIO \\ Department of Orthopaedic Surgery, Faculty of Medicine, Fukuoka University, Fukuoka 814-0180, Japan \\ Received September 10, 2012; Accepted October 4, 2012
}

DOI: $10.3892 / 01.2012 .1002$

\begin{abstract}
Soft tissue tumors are classified according to their histological resemblance to normal adult tissues and can be grouped into the following categories based on metastatic potential: benign, intermediate (locally aggressive), intermediate (rarely metastasizing) and malignant. Over the past two decades, considerable progress has been made in our understanding of the genetic background of soft tissue tumors. Traditional laboratory techniques, such as cytogenetic analysis and fluorescence in situ hybridization (FISH), can be used for diagnostic purposes in soft tissue pathology practice. Moreover, cytogenetic and molecular studies are often necessary for prognostics and follow-up of soft tissue sarcoma patients. This review provides updated information on the applicability of laboratory genetic testing in the diagnosis of benign and intermediate soft tissue tumors. These tumors include nodular fasciitis, chondroid lipoma, collagenous fibroma (desmoplastic fibroblastoma), giant cell tumor of tendon sheath (GCTTS)/pigmented villonodular synovitis (PVNS), angiofibroma of soft tissue, myxoinflammatory fibroblastic sarcoma (MIFS) and ossifying fibromyxoid tumor (OFMT).
\end{abstract}

\section{Contents}

1. Introduction

2. Benign soft tissue tumors

3. Intermediate soft tissue tumors

4. Conclusions

\section{Introduction}

Soft tissue tumors are a highly heterogeneous group of mesenchymal neoplasms that are classified according to the cell type they resemble. Within the various histogenetic categories, soft

Correspondence to: Dr Jun Nishio, Department of Orthopaedic Surgery, Faculty of Medicine, Fukuoka University, 7-45-1 Nanakuma, Jonan-ku, Fukuoka 814-0180, Japan

E-mail: jnishio@cis.fukuoka-u.ac.jp

Key words: cytogenetics, molecular cytogenetics, soft tissue tumor tissue tumors are usually divided into benign, intermediate (locally aggressive), intermediate (rarely metastasizing) and malignant forms (1).

In current practice, cytogenetic and molecular cytogenetic [fluorescence in situ hybridization (FISH)] assays can serve as a useful diagnostic adjunct for soft tissue tumors. Many benign and intermediate soft tissue tumors are characterized by specific cytogenetic translocations or other rearrangements (2). This review provides updated information on the cytogenetic and molecular cytogenetic characteristics of benign and intermediate soft tissue tumors as well as their clinicopathological features, including nodular fasciitis, chondroid lipoma, collagenous fibroma (desmoplastic fibroblastoma), giant cell tumor of tendon sheath (GCTTS)/pigmented villonodular synovitis (PVNS), angiofibroma of soft tissue, myxoinflammatory fibroblastic sarcoma (MIFS) and ossifying fibromyxoid tumor (OFMT). The consistent genetic alterations are summarized in Table I.

\section{Benign soft tissue tumors}

Nodular fasciitis is a mass-forming, self-limited reactive process of unknown pathogenesis. It occurs in all age groups but more often in young adults. Males and females are about equally affected. Most nodular fasciitis arise in the subcutaneous tissues of the upper extremities (especially the volar aspect of the forearm), trunk and head and neck. Nodular fasciitis typically grows rapidly and reaches its final size within a few weeks. It usually measures $\leq 2 \mathrm{~cm}$ in its greatest dimension (1). Soreness, tenderness or slight pain may be present. Histologically, nodular fasciitis is composed of plump, immature-appearing fibroblasts and myofibroblasts lacking nuclear hyperchromasia and pleomorphism. Mitotic figures are fairly common, but atypical mitoses are virtually never evident (3). Due to its rapid growth, high cellularity and high mitotic activity, nodular fasciitis can be misdiagnosed as a malignant soft tissue tumor, especially fibrosarcoma or low-grade myxofibrosarcoma, often leading to unnecessarily aggressive therapy.

Clonal chromosomal aberrations have been detected by cytogenetic analysis in five cases of nodular fasciitis (4-8). Rearrangements involving 3q21 and 15q22-26 have been identified in a subset of nodular fasciitis. Velagaleti et al (8) suggested that FGF7 and NTRK3 are potential candidate target genes for the $15 \mathrm{q}$ rearrangement. A conventional 
Table I. Chromosomal aberrations and associated molecular events in benign and intermediate soft tissue tumors.

\begin{tabular}{|c|c|c|}
\hline Tumor type & Chromosomal aberration & Molecular event \\
\hline \multicolumn{3}{|l|}{ Benign } \\
\hline Nodular fasciitis & $\begin{array}{l}\text { Not assigned } \\
3 q 21 \text { rearrangement } \\
15 q 22-26 \text { rearrangement }\end{array}$ & $\begin{array}{l}\text { USP6 rearrangement } \\
\text { Not known } \\
\text { Not known }\end{array}$ \\
\hline Chondroid lipoma & $\mathrm{t}(11 ; 16)(\mathrm{q} 13 ; \mathrm{p} 13)$ & C11of95-MKL2 \\
\hline Collagenous fibroma & $11 \mathrm{q} 12$ rearrangement ${ }^{\mathrm{b}}$ & FOSL1 rearrangement \\
\hline GCTTS/PVNS & $\begin{array}{l}\text { 1p11-13 rearrangement }{ }^{\mathrm{c}} \\
\text { 16q24 rearrangement } \\
\text { Trisomy } 5 \text { and/or trisomy } 7\end{array}$ & $\begin{array}{l}\text { CSF1 rearrangement } \\
\text { Not known } \\
\text { Not known }\end{array}$ \\
\hline Angiofibroma of soft tissue & $\mathrm{t}(5 ; 8)(\mathrm{p} 15 ; \mathrm{q} 13)$ & AHRR-NCOA2 \\
\hline \multicolumn{3}{|c|}{ Intermediate (locally metastasizing) } \\
\hline $\begin{array}{l}\text { MIFS }^{\mathrm{d}} \\
\text { Ossifying fibromyxoid tumor }\end{array}$ & $\begin{array}{l}\mathrm{t}(1 ; 10)(\mathrm{p} 22 ; \mathrm{q} 24) \\
6 \mathrm{p} 21 \text { rearrangement }^{\mathrm{e}}\end{array}$ & $\begin{array}{l}\text { TGFBR3, MGEA5 rearrangement } \\
\text { PHF1 rearrangement }\end{array}$ \\
\hline
\end{tabular}

${ }^{\mathrm{a}}$ MYH9-USP6 fusion gene is identified in a subset of nodular fasciitis. ${ }^{\mathrm{b}}$ Most preferred rearrangement is $\mathrm{t}(2 ; 11)(\mathrm{q} 31 ; \mathrm{q} 12)$. ${ }^{\mathrm{c}} \mathrm{Most}$ preferred rearrangement is $\mathrm{t}(1 ; 2)(\mathrm{p} 11-13 ; \mathrm{q} 35-37)$ resulting in a COL6A3-CSF1 fusion gene. ${ }^{\mathrm{d}} \mathrm{Ring}$ or marker chromosome, composed of amplified 3p12, is associated with an increased expression of $V G L L 3 .{ }^{e}$ Most preferred rearrangement is $\mathrm{t}(6 ; 12)(\mathrm{p} 21 ; \mathrm{q} 24)$ resulting in an EP400-PHF1 fusion gene. GCTTS/PVNS, giant cell tumor of tendon sheath/pigmented villonodular synovitis; MIFS, myxoinflammatory fibroblastic sarcoma.

comparative genomic hybridization $(\mathrm{CGH})$ study has revealed gains of 10p14-15 and 20q12-13.3 in only one of five nodular fasciitis cases (9). A gene expression analysis has shown higher expression of the SYK, LYN, EPHA4, OAS1, TCF20, MITF, CXCL9, CXCL10, MMP1, MMP9, MMP13, CTSC, CTSL and $P L A U$ genes (10). Bacac et al (10) suggested that nodular fasciitis and desmoid-type fibromatosis may be distinguished on the basis of the expression profile of several gene clusters.

More recently, Erickson-Johnson et al (11) reported that USP6 rearrangements with the formation of the fusion gene MYH9-USP6 occur in most examples of nodular fasciitis. USP6 is located on chromosome $17 \mathrm{p} 13$ and has a limited expression in normal cells. USP6 rearrangements were first identified in aneurysmal bone cyst (ABC) (12). The presence of USP6 rearrangements has also been reported in two cases of ABC-like myositis ossificans (13). However, USP6 rearrangements are absent in its histological mimics in soft tissue, including desmoid-type fibromatosis, fibrosarcoma and myxofibrosarcoma. Therefore, USP6 FISH is an extremely useful adjunct in the diagnosis of nodular fasciitis.

Chondroid lipoma, despite its worrisome histological appearance, is a benign soft tissue tumor with features of both embryonal fat and embryonal cartilage (14). It usually occurs in the third or fourth decade of life with a female predominance. The tumor typically presents as a slow-growing, painless mass in the proximal extremities and limb girdles. Most chondroid lipomas measure $2-7 \mathrm{~cm}$ in their greatest dimension (1). Chondroid lipoma is often deep seated, involving skeletal muscle or deep fibrous connective tissues. Histologically, chondroid lipoma has a lobular pattern and consists of sheets, nests and cords of round cells embedded in a myxoid to hyalinized chondroid matrix, with a variable amount of mature adipose tissue. The cells show cytoplasmic vacuolation or eosinophilic granular cytoplasm. Significant nuclear pleomorphism or mitotic activity is not evident. Chondroid lipoma may be mistaken for a malignant soft tissue tumor, especially myxoid liposarcoma or extraskeletal myxoid chondrosarcoma $(15,16)$.

An identical reciprocal translocation, $\mathrm{t}(11 ; 16)(\mathrm{q} 13 ; \mathrm{p} 13)$, has been detected by cytogenetic analysis in six cases of chondroid lipoma (17-20). Recurrent involvement of 11q13 has also been described in hibernoma, but not in association with 16p13 (15).

In their study, Huang et al (20) reported that the $\mathrm{t}(11 ; 16)$ (q13;p13) translocation results in a fusion of C11orf95 and $M K L 2$. These gene rearrangements have not been identified in other soft tissue tumors thus far, and appear to be characteristic for chondroid lipoma. FISH assay for C11orf95 or MKL2 rearrangements is therefore useful for the differential diagnosis of chondroid lipoma and its histological mimics, particularly when evaluating small samples (20).

Collagenous fibroma, also known as desmoplastic fibroblastoma, is a benign fibrous soft tissue tumor first described by Evans (21) in 1995. This tumor primarily occurs in the subcutaneous tissues or skeletal muscle of upper extremities and has a peak incidence in the fifth to seventh decades of life with a male predominance. Few cases have been encountered in children $(22,23)$. Collagenous fibroma typically presents as a firm, slow-growing, painless mass, measuring $\leq 4 \mathrm{~cm}$ in its greatest dimension (3). Grossly, collagenous fibroma appears as a well-circumscribed mass with a white to gray cut surface (Fig. 1A). Histologically, the lesion is hypocellular and consists of spindle- to stellate-shaped cells embedded in a collagenous or myxocollagenous stroma (Fig. 1B). Mitotic figures are rare or absent and necrosis is not present. Collagenous fibroma may be mistaken for several other benign and low-grade malignant soft tissue tumors, including desmoid-type fibromatosis and low-grade fibromyxoid sarcoma.

Clonal chromosomal aberrations have been detected by cytogenetic analysis in 10 cases of collagenous fibroma 
A

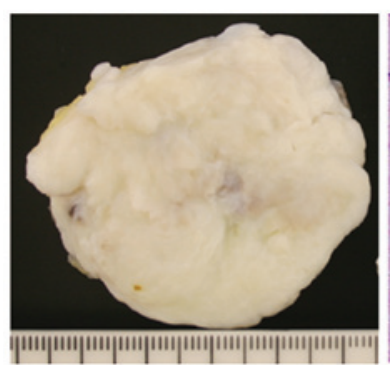

B

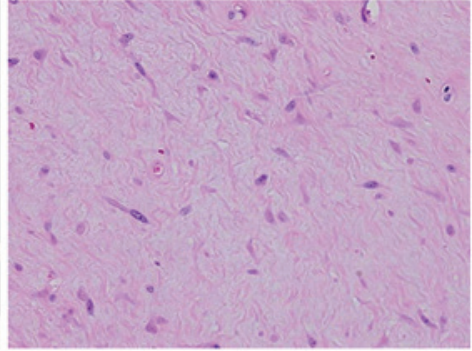

C

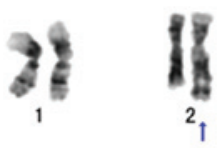

II
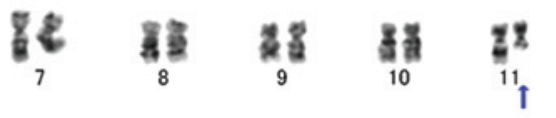

$\underset{12}{\stackrel{3}{*}}$
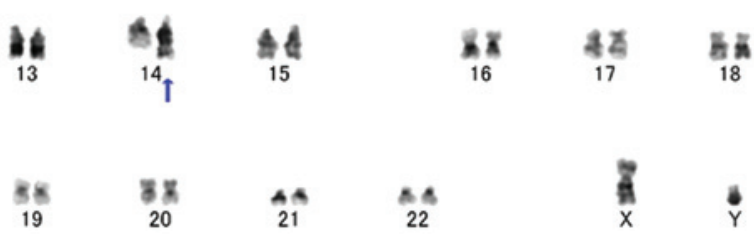

Figure 1. Collagenous fibroma. (A) Gross appearance showing a well-circumscribed mass with a gray-white cut surface. (B) The tumor is composed of spindle- to stellate-shaped cells in a dense collagenous stroma. (C) G-banded karyotype showing a $2 ; 11$ translocation. A $\mathrm{t}(5 ; 14)(\mathrm{q} 15 ; \mathrm{q} 22)$ translocation is evident. Arrows indicate the structural chromosome aberrations.

(24-29). The long arm of chromosome 11, in particular 11q12, is involved in all cases except one (Fig. 1C). Several chromosomal segments have been recognized as translocation partners to $11 \mathrm{q} 12$ and the most preferred rearrangement is $\mathrm{t}(2 ; 11)(\mathrm{q} 31 ; \mathrm{q} 12)$. Notably, the same translocation has also been observed in a case of fibroma of tendon sheath (30), suggesting a pathogenetic link between these two entities.

Macchia et al (29) recently reported that FOSL1 (formerly known as Fra-1) is a candidate target gene for 11q12 rearrangements in collagenous fibroma. This gene is a member of the Fos family and encodes leucine zipper proteins. FOSL1 has been reported to be activated in multiple human carcinomas, including lung, colon, breast, prostate, brain and head and neck cancers (31). However, FOSL1 rearrangements have not been detected in other soft tissue tumors thus far. FOSL1 FISH may therefore be important in the diagnosis of collagenous fibroma.

Tenosynovial giant cell tumor is classified into two types, with different clinical features and biological behavior, although their histological finding is similar (1). The localized type, also known as GCTTS, may occur at any age but has a peak incidence in the third to fourth decades of life with a female predominance. GCTTS usually presents as a painless, slow-growing mass in the extremities, especially the fingers. Grossly, GCTTS is well circumscribed and encapsulated. Recurrences are non-destructive and are easily controlled by re-excision. The diffuse type, also known as PVNS, tends to occur in younger patients and is slightly more common in females. PVNS usually presents as a painful, longstanding mass with hemarthrosis in large joints,
A
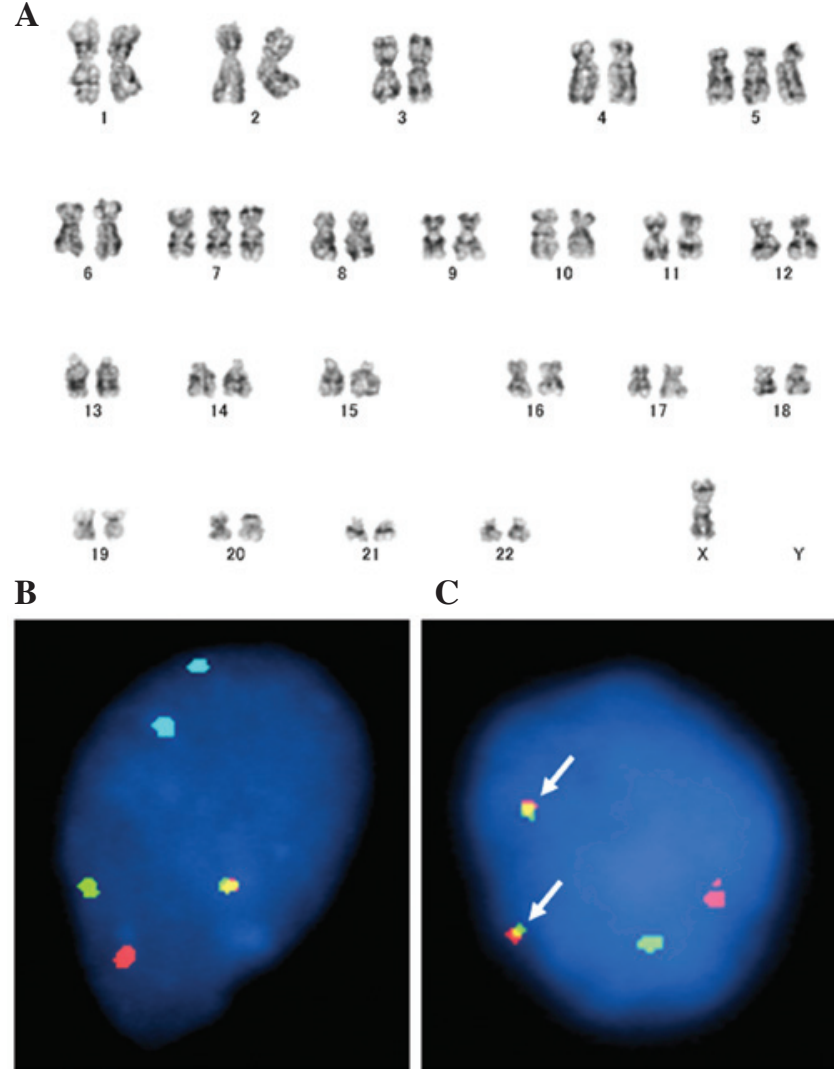

Figure 2. Pigmented villonodular synovitis. (A) G-banded karyotype showing the presence of an extra copy of chromosomes 5 and 7. (B) Fluorescence in situ hybridization (FISH) analysis with custom-designed probes flanking the $C S F 1$ gene (proximal, orange; distal, green) shows a split of the orange and green signals, indicating disruption of CSF1. The aqua signals represent the centromeric region of the chromosome 7 homologues. (C) FISH analysis with custom-designed probes spanning the CSF1 (green) and COL6A3 (orange) genes shows overlapping yellow signals (arrows), confirming the presence of a COL6A3-CSF1 fusion.

especially the knee. Grossly, PVNS is poorly circumscribed and has a prominent villonodular growth pattern. This potentially aggressive lesion frequently recurs, occasionally necessitating radical surgery (1). Histologically, the lesion is composed of sheets of round or polygonal cells admixed with multinucleated giant cells and xanthoma cells with hemosiderin granules. Compared with GCTTS, cleft-like or pseudoglandular spaces are more prominent in PVNS. Mitotic activity is usually present, but atypical mitoses and nuclear atypia are not evident.

Clonal chromosomal aberrations have been detected by cytogenetic analysis in 45 cases of GCTTS/PVNS (32-45). GCTTS/PVNS exhibits mostly simple karyotypes characterized by one or a few chromosomal rearrangements or numerical aberrations. The short arm of chromosome 1, in particular 1p11-13, is frequently involved in GCTTS/PVNS. Several chromosomal segments have been recognized as translocation partners to $1 \mathrm{p} 11-13$ and the most preferred rearrangement is $\mathrm{t}(1 ; 2)(\mathrm{p} 11-13 ; \mathrm{q} 35-37)$ resulting in a COL6A3-CSF1 fusion gene $(46,47)$. In addition, another possible cytogenetic subgroup might be characterized by translocations involving $16 q 24$. Moreover, trisomy for chromosomes 5 and/or 7, usually as the sole anomaly, has been observed only in PVNS (Fig. 2A).

In a previous study, West et al (46) demonstrated that CSF1 at $1 \mathrm{p} 13$ is often rearranged in GCTTS/PVNS. The authors 
also detected high levels of its receptor (CSF1R) expression in most of the cells. However, only a minority of tumor cells (2-16\%) carry the translocation and express CSF1. These findings suggest that aberrant CSF1 signaling is crucial in the pathogenesis of GCTTS/PVNS. CSF1 rearrangements can be detected by FISH (Fig. 2B and C), although probes are not yet commercially available.

Blay et al (48) initially reported a case of recurrent PVNS showing a complete response after imatinib therapy. More recently, Cassier et al (49) reported that the overall response rate of a daily dose of imatinib $(400 \mathrm{mg})$ in patients with locally advanced/metastatic PVNS was 19\%. Moreover, the overall symptomatic response rate was $73 \%$. These results suggest that the use of targeted inhibitors of CSF1R, such as imatinib, are a good therapeutic option in the treatment strategy of locally advanced/metastatic or recurrent PVNS.

Angiofibroma of soft tissue is a distinctive benign fibrovascular soft tissue tumor first described by Mariño-Enríquez and Fletcher (50) in 2012. It usually occurs in middle-aged adults, with a female predominance. Angiofibroma of soft tissue typically presents as a slow-growing, painless, well-defined mass in the extremities, often in relationship to joints or fibrotendinous structures. The lesions range from 1.2 to $12 \mathrm{~cm}$ in their greatest dimension, with a median size of $3.5 \mathrm{~cm}$ (50). Histologically, the tumor consists of a proliferation of relatively uniform, bland spindle cells set in a variably myxoid-to collagenous stroma with a prominent and complex vascular pattern. Mitotic activity is occasionally observed, but cytologic atypia and nuclear hyperchromasia are absent. Immunohistochemically, the neoplastic cells are focally positive for epithelial membrane antigen. Occasional cases may show scattered cells that stain CD34, smooth muscle actin and desmin. Angiofibroma of soft tissue may be mistaken for a number of benign and low-grade malignant soft tissue tumors, including cellular angiofibroma, solitary fibrous tumor, low-grade fibromyxoid sarcoma, low-grade myxofibrosarcoma and myxoid liposarcoma (50).

Clonal chromosomal aberrations have been detected by cytogenetic analysis in seven cases of soft tissue angiofibroma (50-52). A reciprocal translocation, $\mathrm{t}(5 ; 8)(\mathrm{p} 15 ; \mathrm{q} 13)$, has been identified in five cases. A three-way $\mathrm{t}(5 ; 8 ; 8)(\mathrm{p} 15 ; \mathrm{q} 13 ; \mathrm{p} 11)$ translocation has also been described in one case (50). A gene expression analysis has shown higher expression of CYPlAl in angiofibroma of soft tissue compared with myxofibrosarcoma (51).

In their study, Jin et al (51) reported that the $\mathrm{t}(5 ; 8)(\mathrm{p} 15 ; \mathrm{q} 13)$ translocation results in a fusion of AHRR and NCOA2. AHRR is located on chromosome $5 \mathrm{p} 15$ and is not involved in gene fusions. NCOA2 is located on chromosome $8 \mathrm{q} 13$ and has been identified as the 3'-partner in fusions with $P A X 3$ and $H E Y 1$ in soft tissue sarcomas $(53,54)$. However, these gene rearrangements have not been detected in its histological mimics. FISH assay for AHRR or NCOA2 rearrangements can therefore be applied as a reliable laboratory test in the diagnosis of soft tissue angiofibroma.

\section{Intermediate soft tissue tumors}

MIFS is an intermediate (rarely metastasizing) soft tissue tumor first described by Montgomery et al (55) in 1998.
It primarily occurs in the subcutaneous tissues of distal extremities and has a peak incidence in the fourth and fifth decades of life with no gender predilection. MIFS typically presents as a slow-growing, painless, poorly defined mass. The preoperative diagnosis in most cases is benign and may include tenosynovitis, ganglion cyst and GCTTS/PVNS (1). Histologically, MIFS is multinodular, poorly circumscribed and characterized by a prominent myxoid matrix containing numerous inflammatory cells, including lymphocytes, plasma cells, neutrophils and eosinophils (56). Germinal centers are occasionally encountered. Neoplastic cells include spindle-shaped and epithelioid cells with mild to moderate nuclear atypia, large polygonal and bizarre ganglion-like cells, Reed-Sternberg-like cells with huge inclusion-like nucleoli and multivacuolated lipoblast-like cells. Hemosiderin deposition may be evident. Mitotic activity is usually low and necrosis is rarely present. Immunohistochemically, the neoplastic cells are diffusely positive for vimentin and focally for CD68 and CD34. Occasional cases may show scattered cells that stain for cytokeratin or smooth muscle actin. More importantly, immunostains for leukocyte common antigens, CD15 and CD30, are negative (16). MIFS can be histologically mistaken for a number of benign and malignant soft tissue tumors, including GCTTS/PVNS, inflammatory myofibroblastic tumor and myxofibrosarcoma.

Clonal chromosomal aberrations have been detected by cytogenetic analysis in 10 cases of MIFS and hybrid MIFS/hemosiderotic fibrolipomatous tumor (HFLT) (57-63). Cytogenetic and molecular cytogenetic studies have identified the frequent presence of a balanced or unbalanced $t(1 ; 10)$ (p22;q24) translocation and ring or marker chromosomes secondary to 3 p11-12 amplifications. A reciprocal $t(2 ; 6)$ (q31;p21.3) translocation has also been described as the sole anomaly in a single case (59). It is of interest that the $t(1 ; 10)$ translocation has also been identified in three cases of pure HFLT $(61,63,64)$. These findings suggest that MIFS and HFLT likely represent different morphologic variants of the same entity.

Conventional and array $\mathrm{CGH}$ studies have shown the amplification of 3p11-12 (61,65). Notably, Hallor et al (61) demonstrated that 3p11-12 amplification is associated with an increased expression of VGLL3 and CHMP $2 B$. Moreover, Antonescu et al (63) confirmed the presence of high level VGLL3 amplification by FISH in MIFS, as well as in HFLT and cases with hybrid morphology. VGLL3 has been shown to be amplified and overexpressed in undifferentiated pleomorphic sarcoma and dedifferentiated liposarcoma (66). These findings suggest that VGLL3 is the main target of 3p12 amplification and this genetic event may be crucial in the development and progression of certain subsets of soft tissue sarcomas. A gene expression analysis has shown overexpression of NPM3 and particularly FGF8 (61). These two genes have been mapped to $10 \mathrm{q} 24 . F G F 8$ is a member of the fibroblast growth factor family. FGF8 overexpression has been shown to increase tumor growth and angiogenesis (67).

Antonescu et al (63) reported that FISH analysis for TGFBR3 at 1p22 and MGEA5 at 10q24 rearrangements can be applied as a reliable molecular test in the diagnosis of MIFS.

According to the current World Health Organization classification, OFMT is an intermediate (rarely metastasizing) soft 
tissue tumor of uncertain lineage (1). The biological behavior of OFMT varies. OFMT primarily occurs in the extremities, trunk and head and neck of adults with a median age of approximately 50 years (68-70). Males are affected more frequently than females. OFMT typically presents as a slow-growing, painless, well-defined, subcutaneous mass. The lesions range from 1 to $20 \mathrm{~cm}$ in their greatest dimension, with a median size of 3-5 cm (68-70). Histologically, OFMT is composed of uniform round, ovoid, or spindle-shaped cells arranged in nests and cords and deposited in a variably fibromyxoid stroma. In approximately $80 \%$ of cases, there is an incomplete shell of lamellar bone found at the periphery of the nodules (3). Small foci of calcification and metaplastic cartilage are also evident. Mitotic activity is usually less than 1/10 high power fields. Although a majority of OFMTs are histologically benign and show correspondingly benign clinical behavior, it has been recognized that a subset of OFMTs have atypical histological findings, such as high cellularity and/or increased mitotic activity and show correspondingly more aggressive clinical behavior (68,70). Immunohistochemically, the neoplastic cells are typically positive for vimentin and S-100 protein. The cells may also express desmin, CD10, Leu-7, neuron-specific enolase and glial fibrillary acidic protein. OFMT may be mistaken for a number of benign and malignant soft tissue tumors, including chondroid syringoma, low-grade fibromyxoid sarcoma and extraskeletal osteosarcoma.

Clonal chromosomal aberrations have been detected by cytogenetic analysis in seven cases of OFMT $(68,71-74)$. The short arm of chromosome 6 , in particular $6 \mathrm{p} 21$, is frequently involved in OFMT. Notably, a balanced or unbalanced $t(6 ; 12)$ (p21;q24) translocation appears to be characteristic for OFMT. A gene expression analysis has shown overexpression of EAAT4 and underexpression of PMP22 in OFMT compared with nerve sheath myxoma and schwannoma (70). Moreover, Graham et al (70) identified loss of INI-1 at 22q11.2 in five of seven cases by interphase FISH.

Gebre-Medhin et al (74) recently reported that $P H F 1$ at 6 p21 is frequently rearranged in OFMT, including atypical and malignant variants. Moreover, PHF1 was fused to EP400 at $12 q 24$ in one atypical case with the $\mathrm{t}(6 ; 12)$ translocation. OFMT is the second neoplasm, in addition to endometrial stromal tumor, in which PHFl is involved in fusions with ectopic sequences. These findings suggest that FISH assay for PHFl rearrangements serves as an excellent diagnostic tool in ambiguous cases.

\section{Conclusions}

Traditional laboratory techniques, such as cytogenetic analysis and FISH, have a pivotal role in the diagnosis of soft tissue tumors. Over the past few years, some novel gene rearrangements have been described in benign and intermediate soft tissue tumors. Notably, the $\mathrm{t}(5 ; 8)(\mathrm{p} 15 ; \mathrm{q} 13)$ translocation, resulting in the $A H R R-N C O A 2$ fusion gene, was identified in angiofibroma of soft tissue recently proposed as a new clinicopathologic entity (51). FISH can be used to distinguish between entities with similar histological appearances, although probes are not yet commercially available. Understanding the basis of these ancillary techniques and their application is critical to provide accurate diagnoses of soft tissue tumors.

\section{Acknowledgements}

This study was supported in part by Fukuoka Cancer Society, Ogata Foundation and the Foundation for the Promotion of Medical Science.

\section{References}

1. Fletcher CDM, Unni KK and Mertens F (eds): World Health Organization Classification of Tumours: Pathology and Genetics of Tumours of Soft Tissue and Bone. IARC Press, Lyon, France, 2002.

2. Bridge JA and Cushman-Vokoun AM: Molecular diagnostics of soft tissue tumors. Arch Pathol Lab Med 135: 588-601, 2011.

3. Weiss SW and Goldblum JR: Enzinger and Weiss's: Soft Tissue Tumors. Mosby, Philadelphia, 2008.

4. Sawyer JR, Sammartino G, Baker GF and Bell JM: Clonal chromosome aberrations in a case of nodular fasciitis. Cancer Genet Cytogenet 76: 154-156, 1994.

5. Birdsall SH, Shipley JM, Summersgill BM, et al: Cytogenetic findings in a case of nodular fasciitis of the breast. Cancer Genet Cytogenet 81: 166-168, 1995.

6. Weibolt VM, Buresh CJ, Roberts CA, et al: Involvement of 3q21 in nodular fasciitis. Cancer Genet Cy togenet 106: 177-179, 1998.

7. Donner LR, Silva T and Dobin SM: Clonal rearrangement of $15 \mathrm{p} 11.2,16 \mathrm{p} 11.2$ and $16 \mathrm{p} 13.3$ in a case of nodular fasciitis: additional evidence favoring nodular fasciitis as a benign neoplasm and not a reactive tumefaction. Cancer Genet Cytogenet 139: 138-140, 2002.

8. Velagaleti GVN, Tapper JK, Panova NE, Miettinen M and Gatalica Z: Cytogenetic findings in a case of nodular fasciitis of subclavicular region. Cancer Genet Cytogenet 141: 160-163, 2003.

9. Meng GZ, Zhang HY, Zhang Z, Wei B and Bu H: Myofibroblastic sarcoma vs nodular fasciitis: a comparative study of chromosomal imbalances. Am J Clin Pathol 131: 701-709, 2009.

10. Bacac M, Migliavacca E, Stehle JC, et al: A gene expression signature that distinguishes desmoid tumours from nodular fasciitis. J Pathol 208: 543-553, 2006.

11. Erickson-Johnson MR, Chou MM, Evers BR, et al: Nodular fasciitis: a novel model of transient neoplasia induced by MYH9-USP6 gene fusion. Lab Invest 91: 1427-1433, 2011.

12. Oliveira AM, Hsi BL, Weremowicz S, et al: USP6 (Tre2) fusion oncogenes in aneurysmal bone cyst. Cancer Res 64: 1920-1923, 2004.

13. Sukov WR, Franco MF, Erickson-Johnson M, et al: Frequency of USP6 rearrangements in myositis ossificans, brown tumor and cherubism: molecular cytogenetic evidence that a subset of 'myositis ossificans-like lesions' are the early phases in the formation of soft-tissue aneurysmal bone cyst. Skeletal Radiol 37: 321-327, 2008.

14. Thway K, Flora RS and Fisher C: Chondroid lipoma: an update and review. Ann Diagn Pathol 16: 230-234, 2012.

15. Nishio J: Contributions of cytogenetics and molecular cytogenetics to the diagnosis of adipocytic tumors. J Biomed Biotechnol 2011: 524067, 2011.

16. Nishio J, Iwasaki H, Nabeshima $\mathrm{K}$ and Naito M: Cytogenetics and molecular genetics of myxoid soft-tissue sarcomas. Genet Res Int 2011: 497148, 2011.

17. Gisselsson D, Domanski HA, Höglund M, et al: Unique cytological features and chromosome aberrations in chondroid lipoma: a case report based on fine-needle aspiration cytology, histopathology, electron microscopy, chromosome banding and molecular cytogenetics. Am J Surg Pathol 23: 1300-1304, 1999.

18. Thomson TA, Horsman D and Bainbridge TC: Cytogenetic and cytologic features of chondroid lipoma of soft tissue. Mod Pathol 12: 88-91, 1999.

19. Ballaux F, Debiec-Rychter M, De Wever I and Sciot R: Chondroid lipoma is characterized by $\mathrm{t}(11 ; 16)(\mathrm{q} 13 ; \mathrm{p} 12-13)$. Virchows Arch 444: 208-210, 2004.

20. Huang D, Sumegi J, Dal Cin P, et al: C11orf95-MKL2 is the resulting fusion oncogene of $\mathrm{t}(11 ; 16)(\mathrm{q} 13 ; \mathrm{p} 13)$ in chondroid lipoma. Genes Chromosomes Cancer 49: 810-818, 2010.

21. Evans HL: Desmoplastic fibroblastoma: a report of seven cases. Am J Surg Pathol 19: 1077-1081, 1995.

22. Magro G and Venti C: Childhood desmoplastic fibroblastoma (collagenous fibroma) with a 12-year follow-up. Pediatr Dev Pathol 2: 62-64, 1999. 
23. Nishio J, Iwasaki H, Nishijima T and Kikuchi M: Collagenous fibroma (desmoplastic fibroblastoma) of the finger in a child. Pathol Int 52: 322-325, 2002.

24. Sciot R, Samson I, Van Den Berghe H, Van Damme B and Dal Cin P: Collagenous fibroma (desmoplastic fibroblastoma): genetic link with fibroma of tendon sheath? Mod Pathol 12: 565-568, 1999.

25. Bernal K, Nelson M, Neff JR, Nielsen SM and Bridge JA Translocation $(2 ; 11)(\mathrm{q} 31 ; \mathrm{q} 12)$ is recurrent in collagenous fibroma (desmoplastic fibroblastoma). Cancer Genet Cytogenet 149: 161-163, 2004

26. Sakamoto A, Yamamoto H, Yoshida T, et al: Desmoplastic fibroblastoma (collagenous fibroma) with a specific breakpoint of 11q12. Histopathology 51: 859-860, 2007.

27. Maghari A, Ma N, Aisner S, Benevenia J and Hameed M: Collagenous fibroma (desmoplastic fibroblastoma) with a new translocation involving 11q12: a case report. Cancer Genet Cytogenet 192: 73-75, 2009.

28. Nishio J, Akiho S, Iwasaki $\mathrm{H}$ and Naito M: Translocation $\mathrm{t}(2 ; 11)$ is characteristic of collagenous fibroma (desmoplastic fibroblastoma). Cancer Genet 204: 569-571, 2011.

29. Macchia G, Trombetta D, Möller E, et al: FOSL1 as a candidate target gene for 11q12 rearrangements in desmoplastic fibroblastoma. Lab Invest 92: 735-743, 2012.

30. Dal Cin P, Sciot R, De Smet L and Van Den Berghe H Translocation $2 ; 11$ in a fibroma of tendon sheath. Histopathology 32: 433-435, 1998.

31. Young MR and Colburn NH: Fra-1 a target for cancer prevention or intervention. Gene 379: 1-11, 2006.

32. Ray RA, Morton CC, Lipinski KK, Corson JM and Fletcher JA: Cytogenetic evidence of clonality in a case of pigmented villonodular synovitis. Cancer 67: 121-125, 1991.

33. Fletcher JA, Henkle C, Atkins L, Rosenberg AE and Morton CC: Trisomy 5 and trisomy 7 are nonrandom aberrations in pigmented villonodular synovitis: confirmation of trisomy 7 in uncultured cells. Genes Chromosomes Cancer 4: 264-266, 1992.

34. Mertens F, Orndal C, Mandahl N, et al: Chromosome aberrations in tenosynovial giant cell tumors and nontumorous synovial tissue. Genes Chromosomes Cancer 6: 212-217, 1993.

35. Rowlands CG, Roland B, Hwang WS and Sevick RJ: Diffusevariant tenosynovial giant cell tumor: a rare and aggressive lesion. Hum Pathol 25: 423-425, 1994.

36. Dal Cin P, Sciot R, Samson I, et al: Cytogenetic characterization of tenosynovial giant cell tumors (nodular tenosynovitis). Cancer Res 54: 3986-3987, 1994

37. Choong PF, Willen H, Nilbert M, et al: Pigmented villonodular synovitis. Monoclonality and metastasis - a case for neoplastic origin? Acta Orthop Scand 66: 64-68, 1995.

38. Gonzalez-Campora R, Salas Herrero E, Otal-Salaverri C, et al: Diffuse tenosynovial giant cell tumor of soft tissues: report of a case with cytologic and cytogenetic findings. Acta Cytol 39: 770-776, 1995.

39. Dal Cin P, Sciot R, De Smet L, Van Damme B and Van Den Berghe H: A new cytogenetic subgroup in tenosynovial giant cell tumors (nodular tenosynovitis) is characterized by involvement of 16q24. Cancer Genet Cytogenet 87: 85-87, 1996.

40. Ohjimi $Y$, Iwasaki $H$, Ishiguro $M$, et al: Short arm of chromosome 1 aberration recurrently found in pigmented villonodular synovitis. Cancer Genet Cytogenet 90: 80-85, 1996.

41. Sciot R, Rosai J, Dal Cin P, et al: Analysis of 35 cases of localized and diffuse tenosynovial giant cell tumor: a report from the chromosomes and morphology (CHAMP) study group. Mod Pathol 12: 576-579, 1999.

42. Nilsson M, Hoglund M, Panagopoulos I, et al: Molecular cytogenetic mapping of recurrent chromosomal breakpoints in tenosynovial giant cell tumors. Virchows Arch 441: 475-480, 2002.

43. Ferrer J, Namiq A, Carda C, Lopez-Gines C, Tawfik O and Llombart-Bosch A: Diffuse type of giant-cell tumor of tendon sheath: an ultrastructural study of two cases with cytogenetic support. Ultrastruct Pathol 26: 15-21, 2002.

44. Brandal P, Bjerkehagen B and Heim S: Molecular cytogenetic characterization of tenosynovial giant cell tumors. Neoplasia 6: $578-583,2004$

45. Occhipinti E, Heinrich SD and Craver R: Giant cell tumor of tendon sheath arising in the toe. Fetal Pediatr Pathol 23: 171-179, 2004

46. West RB, Rubin BP, Miller MA, et al: A landscape effect in tenosynovial giant-cell tumor from activation of CSF1 expression by a translocation in a minority of tumor cells. Proc Natl Acad Sci USA 103: 690-695, 2006.
47. Moller E, Mandahl N, Mertens F and Panagopoulos I: Molecular identification of COL6A3-CSF1 fusion transcripts in tenosynovial giant cell tumors. Genes Chromosomes Cancer 47: 21-25, 2008.

48. Blay JY, El Sayadi H, Thiesse P, Garret J and Ray-Coquard I: Complete response to imatinib in relapsing pigmented villonodular synovitis/tenosynovial giant cell tumor (PVNS/TGCT). Ann Oncol 19: 821-822, 2008.

49. Cassier PA, Gelderblom H, Stacchiotti S, et al: Efficacy of imatinib mesylate for the treatment of locally advanced and/or metastatic tenosynovial giant cell tumor/pigmented villonodular synovitis. Cancer 118: 1649-1655, 2012.

50. Mariño-Enríquez A and Fletcher CDM: Angiofibroma of soft tissue: clinicopathologic characterization of a distinctive benign fibrovascular neoplasm in a series of 37 cases. Am J Surg Pathol 36: 500-508, 2012

51. Jin Y, Möller E, Nord KH, et al: Fusion of the AHRR and NCOA2 genes through a recurrent translocation $\mathrm{t}(5 ; 8)(\mathrm{p} 15 ; \mathrm{q} 13)$ in soft tissue angiofibroma results in upregulation of aryl hydrocarbon receptor target genes. Genes Chromosomes Cancer 51: 510-520, 2012.

52. Schoolmeester JK, Sukov WR, Aubry MC and Folpe AL: Angiofibroma of soft tissue: core needle biopsy diagnosis, with cytogenetic confirmation. Am J Surg Pathol 36: 1421-1423, 2012.

53. Sumegi J, Streblow R, Frayer RW, et al: Recurrent $\mathrm{t}(2 ; 2)$ and $\mathrm{t}(2 ; 8)$ translocations in rhabdomyosarcoma without the canonical PAX-FOXO1 fuse PAX3 to members of the nuclear receptor transcriptional coactivator family. Genes Chromosomes Cancer 49: 224-236, 2010

54. Wang L, Motoi T, Khanin R, et al: Identification of a novel, recurrent HEY1-NCOA2 fusion in mesenchymal chondrosarcoma based on a genome-wide screen of exon-level expression data. Genes Chromosomes Cancer 51: 127-139, 2012

55. Montgomery EA, Devaney KO, Giordano TJ and Weiss SW: Inflammatory myxohyaline tumor of distal extremities with virocyte or Reed-Sternberg-like cells: a distinctive lesion with features simulating inflammatory conditions, Hodgkin's disease and various sarcomas. Mod Pathol 11: 384-391, 1998.

56. Meis-Kindblom JM and Kindblom LG: Acral myxoinflammatory fibroblastic sarcoma: a low-grade tumor of the hands and feet. Am J Surg Pathol 22: 911-924, 1998.

57. Lambert I, Debiec-Rychter M, Guelinckx P, Hagemeijer A and Sciot R: Acral myxoinflammatory fibroblastic sarcoma with unique clonal chromosomal changes. Virchows Arch 438: 509-512, 2001.

58. Mansoor A, Fidda N, Himoe E, Payne M, Lawce H and Magenis RE: Myxoinflammatory fibroblastic sarcoma with complex supernumerary ring chromosomes composed of chromosome 3 segments. Cancer Genet Cytogenet 152: 61-65, 2004.

59. Ida CM, Rolig KA, Hulshizer RL, et al: My xoinflammatory fibroblastic sarcoma showing $\mathrm{t}(2 ; 6)(\mathrm{q} 31 ; \mathrm{p} 21.3)$ as a sole cytogenetic abnormality. Cancer Genet Cytogenet 177: 139-142, 2007.

60. Gonzalez-Cámpora R, Ríos-Martín JJ, Solórzano-Amoretti A, et al: Fine needle aspiration cytology of an acral myxoinflammatory fibroblastic sarcoma: case report with cytological and cytogenetic findings. Cytopathology 19: 118-123, 2008.

61. Hallor KH, Sciot R, Staaf J, et al: Two genetic pathways, $t(1 ; 10)$ and amplification of 3p11-12, in myxoinflammatory fibroblastic sarcoma, haemosiderotic fibrolipomatous tumour and morphologically similar lesions. J Pathol 217: 716-727, 2009.

62. Elco CP, Mariño-Enríquez A, Abraham JA, Dal Cin P and Hornick JL: Hybrid myxoinflammatory fibroblastic sarcoma/hemosiderotic fibrolipomatous tumor: report of a case providing further evidence for a pathogenetic link. Am J Surg Pathol 34: 1723-1727, 2010.

63. Antonescu CR, Zhang L, Nielsen GP, Rosenberg AE, Dal Cin P and Fletcher CD: Consistent $\mathrm{t}(1 ; 10)$ with rearrangements of TGFBR3 and MGEA5 in both myxoinflammatory fibroblastic sarcoma and hemosiderotic fibrolipomatous tumor. Genes Chromosomes Cancer 50: 757-764, 2011.

64. Wettach GR, Boyd LJ, Lawce HJ, Magenis RE and Mansoor A Cytogenetic analysis of a hemosiderotic fibrolipomatous tumor. Cancer Genet Cytogenet 182: 140-143, 2008.

65. Baumhoer D, Glatz K, Schulten HJ, et al: Myxoinflammatory fibroblastic sarcoma: investigations by comparative genomic hybridization of two cases and review of the literature. Virchows Arch 451: 923-928, 2007.

66. Hélias-Rodzewicz Z, Pérot G, Chibon F, et al: YAP1 and VGLL3, encoding two cofactors of TEAD transcription factors, are amplified and overexpressed in a subset of soft tissue sarcomas. Genes Chromosomes Cancer 49: 1161-1171, 2010. 
67. Mattila MM and Härkönen PL: Role of fibroblast growth factor 8 in growth and progression of hormonal cancer. Cytokine Growth Factor Rev 18: 257-266, 2007.

68. Folpe AL and Weiss SW: Ossifying fibromyxoid tumor of soft parts: a clinicopathologic study of 70 cases with emphasis on atypical and malignant variants. Am J Surg Pathol 27: 421-431, 2003.

69. Miettinen M, Finnell V and Fetsch JF: Ossifying fibromyxoid tumor of soft parts - a clinicopathologic and immunohistochemical study of 104 cases with long-term follow-up and a critical review of the literature. Am J Surg Pathol 32: 996-1005, 2008.

70. Graham RP, Dry S, Li X, et al: Ossifying fibromyxoid tumor of soft parts: a clinicopathologic, proteomic and genomic study. Am J Surg Pathol 35: 1615-1625, 2011.
71. Sovani V, Velagaleti GVN, Filipowicz E, Gatalica Z and Knisely AS: Ossifying fibromyxoid tumor of soft parts: report of a case with novel cytogenetic findings. Cancer Genet Cytogenet 127: 1-6, 2001.

72. Nishio J, Iwasaki H, Ohjimi Y, et al: Ossifying fibromyxoid tumor of soft parts: cytogenetic findings. Cancer Genet Cytogenet 133: 124-128, 2002.

73. Kawashima H, Ogose A, Umezu H, et al: Ossifying fibromyxoid tumor of soft parts with clonal chromosomal aberrations. Cancer Genet Cytogenet 176: 156-160, 2007.

74. Gebre-Medhin S, Nord KH, Möller E, et al: Recurrent rearrangement of the PHF1 gene in ossifying fibromyxoid tumors. Am J Pathol 181: 1069-1077, 2012. 